\title{
The Use of Data Envelopment Analysis to Select Financial Strategies for Industrial Enterprises
}

\author{
Oksana Savko \\ Department of Applied Economics \\ Ivano-Frankivsk National Technical \\ University of Oil and Gas \\ Ivano-Frankivsk, Ukraine \\ http://orcid.org/0000-0002-7282-7731 \\ Iryna Bodnaruk \\ Department of Economics and \\ Management Theory \\ Ivano-Frankivsk National Technical \\ University of Oil and Gas \\ Ivano-Frankivsk, Ukraine \\ irynab25@ukr.net
}

\author{
Ivanna Melnychuk \\ Department of Applied Economics \\ Ivano-Frankivsk National Technical \\ University of Oil and Gas \\ Ivano-Frankivsk, Ukraine \\ http://orcid.org/0000-0003-3425-2575
}

\author{
Vitalii Sharko \\ Department of Commodity Science, \\ Expertise and Commercial Business \\ Vinnytsya Institute of Trade and \\ Economics of KyivNational University \\ of Trade and Economics \\ Vinnytsya, Ukraine \\ http://orcid.org/0000-0001-5830-8911
}

Abstract - The expediency of Data Envelopment Analysis (DEA) usage for gas distribution system (GDS) operators of Ukraine has been substantiated. Such enterprises were estimated and allocated by their degree of efficiency and profitability. This allows to trace changes at the enterprises profitability and the use of resources in comparison with other GDS operators and to form an effective financial strategy. The GDS operators have been divided into 4 groups and variants of strategies for the investigated enterprises have been proposed on the basis of the "profitability - superefficiency" matrix. These variants of strategies are: investment strategy (focused on investing in energy saving technologies, enterprise property, increasing competitiveness and growth of the enterprises market value), diversification strategy (provides for finding ways to increase the superefficiency index through the introduction of expansion of additional services provision, as well as analysis of the main sources of financial activity and its results to ensure the enterprises financial sustainability), cost reduction strategy (aimed at eliminating all factors leading to a negative financial result, as well as revising the main cost items of operating activities and searching for reserves for their optimization) and anti-crisis strategy (involves the action development to minimize insolvency risks, financial and economic diagnostics and consideration of enterprise's reorganization and restructuring possibilities).

Keywords-gas distribution system operators, data envelopment analysis, financial strategies, efficiency valuation

\section{INTRODUCTION}

The market conditions current state presupposes the availability of methods and ways for identifying and neutralizing threats in the enterprises activities, which leads to the need to find new approaches to their management. In conditions of dynamic changes in the external environment, the progressiveness of information technologies, responsibility for making high-quality management decisions that affect the results of operations, there is a need to assess the performance of enterprises. An important condition for such an assessment is that it serves as the basis for making strategic decisions at the level of the formation and implementation of the corporate, and hence the enterprise's financial strategy. This is especially important in industries with a high degree of monopoly power, namely, in the activities of gas distribution system operators (GDS operators). These enterprises are an important and integral component of the gas transmission system of Ukraine and the oil and gas complex as a whole; therefore, their efficiency affects both the consumers' standard of living and the national production efficiency.

\section{MATERIALS AND METHODS}

The Data Envelopment Analysis (DEA) is one of the methods for analyzing the overall performance of business entities. It is used in different sectors and industries during recent years, for example: authors introduced DEA method for energy efficiency analysis [1-3], for gas distribution enterprises performance evaluation [4], benchmarking [5] and ranking [6]. This method is based on a methodology for assessing overall efficiency (productivity) and benchmarking concept, which allows for a comparative assessment of enterprises within the region, identify reserves for improving efficiency, and contribute to improving the internal potential usage.

The DEA method provides for the presence of input and output parameters. When assessing the optimal ratio of the utility function of the input(s) with the utility function of the output(s), there are chosen research objects (Decision Making Units, DMU, decision-making subjects) that provide the maximum output per unit input in the DEA methodology. Such "reference" decision-making subjects are used to compare with other subjects in terms of their use of input resources. These efficient enterprises form the so-called "production efficiency limits". The definition of "production efficiency limits" makes it possible to compare the resources of a single enterprise across the whole set of other enterprises indicators based on the use of linear programming methods. Also, when applying this method, the main benchmarking postulate is used: "in order to find an effective solution in the field of competition, it is necessary to know the best experience of other companies that have achieved success in similar conditions". 
This method has several advantages [7-9]:

- to assess the effectiveness of DMU compared with other similar subjects;

- based on the use of linear programming capabilities to create non-parametric surfaces, to implement the assumption that all enterprises included in the totality of the studied objects have equal access to the same number of the same types of resources;

- the simultaneous use of both cost and natural quantities, which allows you to summarize the many different input and output parameters;

- to determine an enterprise - a "standard" for each DMU, and the object under study must align itself with this enterprise in order to achieve high efficiency;

- the possibility, on the basis of the information studied, to timely identify possible directions for improving the efficiency of economic systems;

- objects of analysis can be the ones that have a significant amount of various resources at the input and output.

One of the main disadvantages of DEA is the fact that the proportion of a small number of units in relation to the number of inputs and outputs may lead to untrustworthy results. Another disadvantage is that DEA is a deterministic method without the possibility of calculation of measurement errors and statistical noise [10].

As a result, the conclusions regarding the functioning of the decision-making subject (employee, production unit, enterprise, industry, region) can and should be used to assess the management quality, including over time, to determine the most effective or optimal ratio of input parameters (for example, ownership structure) and etc.

The first DEA model was introduced in 1978 by Charnes, Cooper, Rhodes - CCR-model [11] and was based on a constant increase in production.

Charnes, Cooper, Rhodes (CCR) model is as follows [11]. $\mathrm{CCR}_{\mathrm{p}}$ model-Output with the reserve variable:

$$
\max \varphi_{0}+\varepsilon\left(\sum_{j=1}^{S} S_{j}^{+}+\sum_{i=1}^{r} S_{j}^{-}\right)
$$

under conditions: $y_{j 0} \varphi_{0}-\sum_{m=1}^{n} y_{j m} \lambda_{m}+S_{r}^{+}=0$; for all companies $j=1, \ldots, \quad s ; \quad \sum_{m=1}^{n} x_{i m} \lambda_{m}+S_{i}^{-}=x_{i 0} \quad ;$ for all firms, $m=1, \ldots, n$; $\lambda_{m}, \mathrm{~S}_{\mathrm{j}}^{+}, \mathrm{S}_{\mathrm{j}}^{-} \geq 0, \mathrm{~m}=1,2, \ldots ., \mathrm{n}$.

$\mathrm{CCR}_{\mathrm{p}}$ model-Input with the reserve variable has a form:

$$
\min \theta_{0}, \lambda_{\mathrm{j}}-\varepsilon\left(\sum_{\mathrm{j}=1}^{\mathrm{S}} S_{j}^{+}+\sum_{i=1}^{r} S_{j}^{-}\right)
$$

under conditions: $\sum_{m=1}^{n} y_{j m} \lambda_{m}-S_{j}^{+}=y_{j 0}$; for all enterprises $j=1, \ldots, s ; \quad x_{i 0} \theta_{0}-\sum_{m=1}^{n} x_{i n} \lambda_{m}-S_{i}^{-}=0 \quad$ for $\quad$ all companies $m=1, \ldots, n ; \lambda_{m}, \mathrm{~S}_{\mathrm{j}}^{+}, \mathrm{S}_{\mathrm{j}}^{-} \geq 0, \mathrm{~m}=1,2, \ldots, \mathrm{n}$,

where $n$ is the number of companies being compared; $r$ is the number of input parameters; $s$ is the number of output parameters; $\varphi_{0}$ is the maximum efficiency of the output parameter; $\theta_{0}$ is the minimum efficiency of the input parameter; $x_{i 0}$ is the i-th input factor of the investigated enterprise; $x_{i m}$ is the $\mathrm{i}$-th input factor of the $\mathrm{m}$-th enterprise with $\mathrm{i}=1, \ldots, \mathrm{r}$ and $\mathrm{m}=1, \ldots, \mathrm{n} ; y_{j 0}$ is the $j$-th output factor of the investigated enterprise; $y_{j m}$ is the $j$-th output factor of the $m$-th enterprise with $i=1, \ldots, r$ and $m=1, \ldots, n ; \lambda_{m}$ are weights coefficients; $S_{j}^{+}, \mathrm{S}_{\mathrm{i}}^{-}$are reserve variables; $\varepsilon$ is nonarchimedean variable equal to a very small value (for practical calculations, the value $10-6$ is assumed).

In this model, virtual inputs and outputs are determined based on weighting factors, which are calculated using linear programming. The weighting factors are calculated in such a way that the researched enterprise takes the value of efficiency on a scale from 0 (ineffective enterprise) to 1 (effective enterprise) and, based on the ratio of incoming and outcoming parameters of the objects under study, this value is maximum. The constant effect of the production scale, on which this model is based, means that the input parameter changes the output parameter proportionally as it changes.

A model with a variable production scale was first formulated by Banker, Charnes, Cooper - BCC model) in 1984 [12]. Changing the input parameter in this model can lead to a disproportionate change in the output parameter. Compared to the CCR model, an additional condition $\sum_{m=1}^{n} \lambda_{m}=1$ has been added to the BCC model, due to which the production function convexity is achieved.

Based on the construction features using BCC models, it is possible to divide technical efficiency into the technical efficiency due to the technical progress phenomena and the efficiency depending on the effect of scale. To determine the scale effect, the following formula is used [13]:

$$
S E=\frac{T E_{C R S}}{T E_{V R S}},
$$

where TECRS is technical efficiency for a model with a constant-return-to-scale (CRS); TEVRS is technical efficiency for a model with a variable-return-to-scale (VRS).

Taking into account the DEA models individual shortcomings, namely the fact that efficiency is in the range $[0,1]$, and efficient companies take efficiency values of 1 and thus exclude the possibility of qualitative ranking, in 1993 Andersen and Petersen proposed the DEA superefficiency model, which does not mathematically differ from the $\mathrm{BCC}$ model, provided that the investigated enterprise is not taken into account when building the efficiency boundaries [14]. 


\section{RESULTS}

On the basis of the DEA technique, an analysis of the GDS operators' activity effectiveness of Ukraine has been made. Considering the fact that GDS operators are monopolists in their field and their activities are regulated by the National Commission for State Regulation of Energy and Public Utilities (NCSREPU), the management of these companies can directly affect only the efficiency of input resources. Therefore, during the analysis, DEA models have been used, which are focused on assessing the efficiency of using input-oriented resources. The purpose of this analysis was to divide the investigated companies into more and less effective, and at the next stage of the study compare the results of the distribution with profitability indicators. According to the financial statements of companies, the analysis of the GDS operators' management effectiveness on the use of available resources to achieve key performance indicators has been carried out. The following parameters characterizing the availability of labor resources and means of labor have been used as input parameters. The wage bill or the number of employees has been used to characterize the availability of labor resources. In our study, we have used the wage bill indicators as a more universal indicator, since according to the total number of employees it is not possible to distinguish between their qualifications and experience (managers, employees, workers), at the same time, the wage bill describes the cost of their labor, depending on their qualifications and experience. The indicator of "residual value of fixed assets, thousand UAH" has been used to characterize the means of labor. This indicator in terms of value fully reflects the ability of an economic unit to carry out the main type of activity. The cost of sales is characterized by the level of use of material resources used for the GDS operators main activity. The indicators of "gas distribution volume, million cubic meters" and "net income (revenue) from sales of products, thousand UAH" have been used as output parameters (Fig. 1). These indicators sufficiently characterize the results of operating activities of the studied companies.

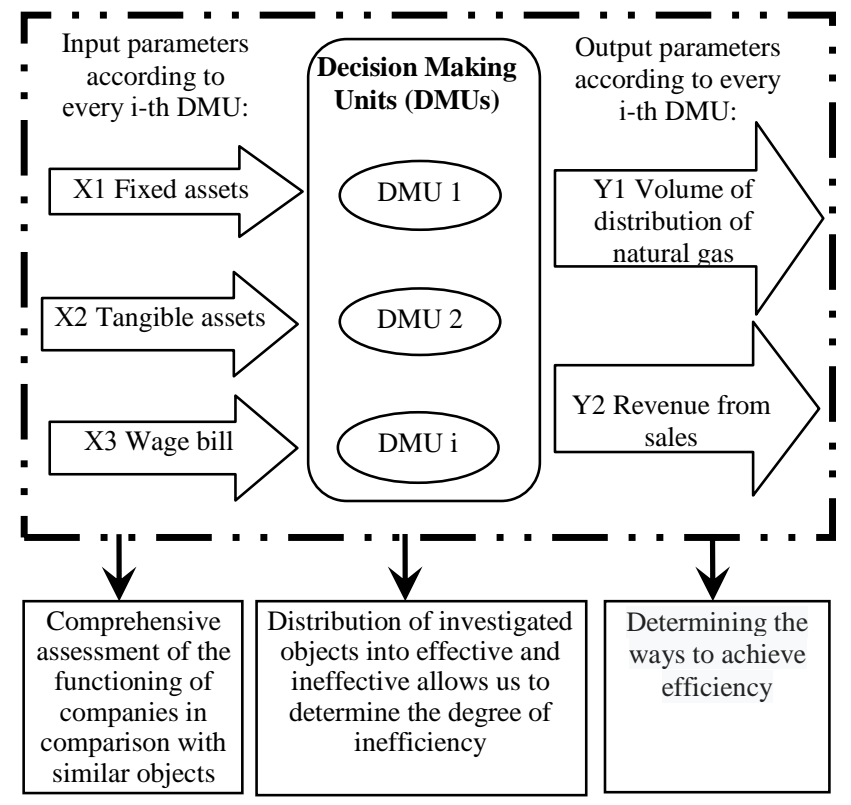

Fig. 1. Diagram of the DEA method usage for evaluating the performance of gas distribution system operators
Stata v.11.0 software has been used to calculate the DEA performance indicators (CCR and BCC models), and the Efficiency Management System (EMS) v.1.3 software has been used to calculate the superefficiency indicator. According to the calculation results, it has been established that the overwhelming majority of companies have a decreasing effect of the production scale, its average value for a wide range of these companies as a whole has been 0.736. This means that with an increase in input parameters, the output will not increase in direct proportion; accordingly, a decrease in the efficiency of the activity (production) is expected (Table I).

TABLE I. RESULTS OF THE ANALYSIS OF THE EFFECTIVENESS OF GDS OPERATORS BY THE METHOD OF DATA ENVELOPMENT ANALYSIS (DEA)

\begin{tabular}{|c|c|c|c|c|}
\hline DMUi & Superefficiency & Rank & \multicolumn{2}{|c|}{ Scale effect } \\
\hline Average value & 1.175 & - & 0.736 & - \\
\hline DMU1 & 0.807 & 24 & 0.747 & $\downarrow$ \\
\hline DMU2 & 0.944 & 21 & 0.540 & $\downarrow$ \\
\hline DMU3 & 9.990 & 1 & 0.547 & $\downarrow$ \\
\hline DMU4 & 1.299 & 11 & 0.820 & $\downarrow$ \\
\hline DMU5 & 1.443 & 10 & 1.000 & $\rightarrow$ \\
\hline DMU6 & 3.824 & 4 & 0.639 & $\downarrow$ \\
\hline DMU7 & 1.031 & 16 & 0.836 & $\downarrow$ \\
\hline DMU8 & 0.833 & 23 & 0.943 & $\downarrow$ \\
\hline DMU9 & 0.739 & 27 & 0.655 & $\downarrow$ \\
\hline DMU10 & 1.913 & 8 & 0.632 & $\uparrow$ \\
\hline DMU11 & 0.580 & 35 & 0.714 & $\downarrow$ \\
\hline DMU12 & 0.957 & 20 & 0.834 & $\downarrow$ \\
\hline DMU13 & 0.545 & 36 & 0.432 & $\uparrow$ \\
\hline DMU14 & 0.630 & 32 & 0.652 & $\downarrow$ \\
\hline DMU15 & 0.706 & 28 & 0.565 & $\uparrow$ \\
\hline DMU16 & 0.769 & 25 & 0.704 & $\downarrow$ \\
\hline DMU17 & 9.990 & 1 & 0.522 & $\downarrow$ \\
\hline DMU18 & 1.098 & 14 & 0.601 & $\downarrow$ \\
\hline DMU19 & 0.669 & 29 & 0.581 & $\downarrow$ \\
\hline DMU20 & 0.501 & 37 & 0.606 & $\downarrow$ \\
\hline DMU21 & 9.990 & 1 & 0.718 & $\downarrow$ \\
\hline DMU22 & 1.227 & 12 & 0.557 & $\downarrow$ \\
\hline DMU23 & 0.998 & 17 & 0.603 & $\uparrow$ \\
\hline DMU24 & 2.580 & 6 & 1.000 & $\rightarrow$ \\
\hline DMU25 & 0.605 & 34 & 0.975 & $\uparrow$ \\
\hline DMU26 & 0.648 & 30 & 0.751 & $\downarrow$ \\
\hline DMU27 & 0.631 & 31 & 0.605 & $\downarrow$ \\
\hline DMU28 & 0.964 & 19 & 0.610 & $\downarrow$ \\
\hline DMU29 & 3.021 & 5 & 1.000 & $\rightarrow$ \\
\hline DMU30 & 1.113 & 13 & 0.465 & $\downarrow$ \\
\hline DMU31 & 0.998 & 18 & 0.861 & $\downarrow$ \\
\hline DMU32 & 0.742 & 26 & 0.761 & $\downarrow$ \\
\hline DMU33 & 0.931 & 22 & 0.778 & $\downarrow$ \\
\hline DMU34 & 2.446 & 7 & 1.000 & $\rightarrow$ \\
\hline DMU35 & 1.869 & 9 & 0.913 & $\downarrow$ \\
\hline DMU36 & 1.046 & 15 & 0.844 & $\uparrow$ \\
\hline DMU37 & 0.394 & 38 & 0.995 & $\uparrow$ \\
\hline DMU38 & 0.621 & 33 & 0.648 & $\downarrow$ \\
\hline
\end{tabular}

Big - leaders (DMU3, DMU17, DMU21) are enterprises that cannot be compared with others. It is impossible for them to select the "standard", since their numerical value of superefficiency is the highest. As a rule, such enterprises should either have the lowest values of input indicators, or maximum values of output indicators. They will be most effective in the case of any changes in the input parameters (in the case of an input-oriented analysis model) or output parameters (in the case of an output-oriented analysis model). The analysis of big leaders is carried out depending 
on their citation as "ideals" for other objects of analysis. If a big leader is defined as an ideal enterprise, this indicates that it is super effective as a result of applying the best practice in carrying out activities, otherwise, if it is not ideal, then the impossibility of determining the value of its superefficiency depends solely on the mathematical properties of the objects system, which is studied. It should be noted that big - leaders reduce the scale of production, that is, with a decrease in costs, their productivity will increase.

Studies show that DMU5, DMU24, DMU29, DMU34 have an optimal production scale, and DMU10, DMU13, DMU15, DMU 23 DMU25, DMU36, DMU37 have an upscaling production, which indicates the prospect of their development with increasing input activity parameters. The rest of the companies are operators of gas distribution networks of the regional or city level and have a decreasing production scale; a decrease in the scale of activities will lead them to an improvement in performance indicators.

To determine the methodological approaches to the formation of the financial strategy of an individual enterprise for gas distribution system operators, it is advisable to use the approach proposed by R. Dyson [15]. The essence of this approach is to divide enterprises into 4 groups depending on the values of their superefficiency and profitability, as shown in Fig. 2. The return on assets is used in the title or heads unless they are unavoidable as a measure of profitability.

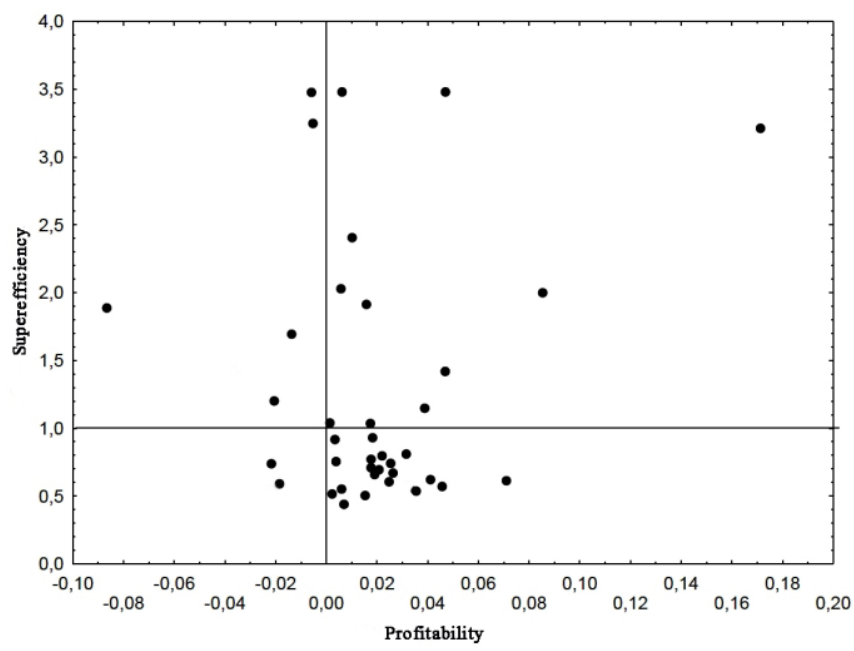

Fig. 2. Matrix "profitability - superefficiency" for gas distribution systems operators based on the results of their activities

\section{DISCUSSION}

It should be noted that under the conditions of the natural monopoly, the alternative choice of strategies is limited for a monopolist from the competition market and therefore the most likely and practical options for strategic choice are such strategies for the monopolist as: investment strategy, cost reduction strategy, diversification strategy and anti-crisis strategy. Such a financial strategies classification determines to the greatest extent the set of tools and goals of natural monopolists, and it provides both an increase in the efficiency of their activities, and also allows the development and implementation of appropriate financial policies for enterprises. The focus of the toolkit within each type of the proposed financial strategy is differentiated by its focus and an integrated approach to solving actual management problems. So, depending on the enterprises place in the quadrant of the "profitability - superefficiency" matrix ("stars", "potential stars", "nonprofitable", "losers"), the enterprise's management must choose the strategy of the enterprise, in particular its financial component.

We propose such financial strategic directions of the enterprises activity, depending on whether they fall into one of the above categories (Fig. 3).

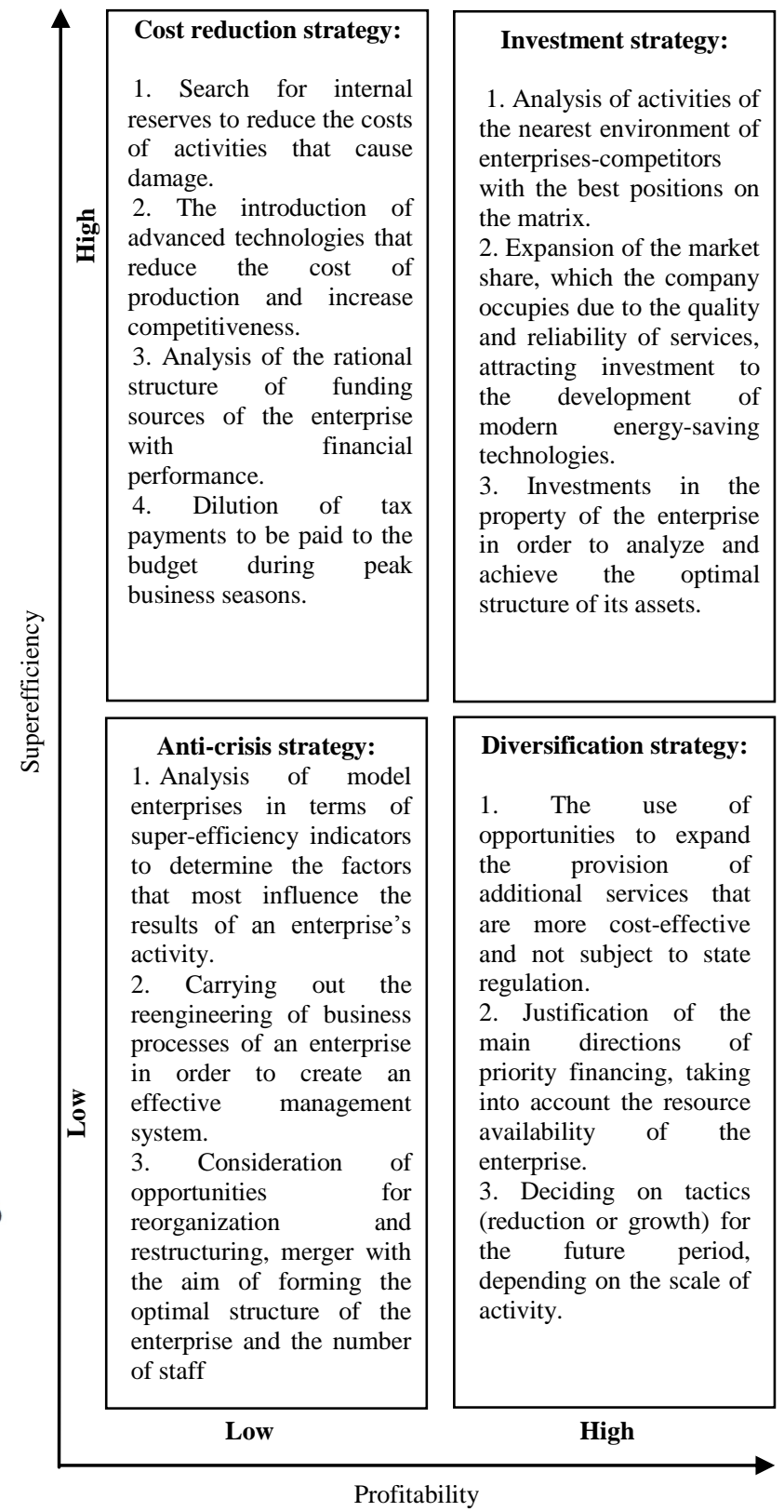

Fig. 3. Types of financial strategy for GDS operators on the basis of evaluating their efficiency

"Star" enterprises are characterized as enterprises that, at the time of the research, chose the best practice of operation and at the same time achieve both technical efficiency of activities and profitability. Such enterprises have the best positions on the matrix of "profitability - superefficiency". For them, it is worth choosing an investment strategy, which is mainly focused on investing in energy-saving technologies, which will reduce production costs; investment in the property of the enterprise that will provide the level of 
solvency and liquidity; on the basis of evaluating the effectiveness of activities, determine ways to improve competitiveness and increase the market value of the enterprise.

"Nonprofit" enterprises have high values of superefficiency on the matrix, however, have low or negative return on assets according to the results of the analysis. For them, it is worth choosing a "cost reduction strategy", which is primarily aimed to eliminate all factors leading to a negative financial result. The difference of such strategy from the strategy for the "stars" quadrant is the absence of additional costs (investments) for the qualitative development of the enterprise in obtaining optimal financial results.

According to the results of research for such a large group of enterprises as "potential stars" for which, according to the matrix, a high economic profitability but low superefficiency is typical, in our opinion, it is advisable to choose a diversification strategy. As part of the financial strategy, this strategy involves finding ways to increase the superefficiency index by introducing or expanding the provision of additional services, as well as analyzing the main sources of financial activity and its results to ensure the financial sustainability of the enterprise.

When forming the anti-crisis strategy, it is necessary to develop a set of actions to minimize insolvency risks, diagnose the financial condition and consider possibilities for reorganizing and restructuring the enterprise. It is worth noting that when developing an anti-crisis strategy, it is advisable to use the main recommendations provided for the strategy of the diversification strategy and the cost reduction strategy, which will allow us to search for ways to increase the superefficiency index and increase the profitability of activities.

\section{CONCLUSIONS}

The expediency of using DEA method for GDS operators based on the analysis of evaluating the performance of business entities is substantiated. The paper uses DEA models which are focused on assessing the efficiency of using input-oriented resources for Ukrainian enterprises with the estimation of superefficiency. It is recommended to use the "profitability - superefficiency" matrix to justify the choice of the type of financial strategy for enterprise. The distribution of GDS operators has been carried out according to their degree of efficiency and profitability; this allows tracking changes that have occurred at the enterprise from the standpoint of technical use of resources and their level of profitability compared to other GDS operators and form an effective financial strategy.

It should be noted that the proposals presented within each type of financial strategy have common characteristics, namely: ensuring the financial security of the enterprise, optimal and rational use of financial resources, the formation and implementation of the main directions of investment programs for the development of activities and the use of basic control elements to manage financial and economic activities of the enterprise, which will improve the efficiency of operation and increase the enterprise market value.

\section{REFERENCES}

[1] M. J. Rezaee, A. Moini, and A. Makui, "Operational and nonoperational performance evaluation of thermal power plants in Iran: A game theory approach," Energy, vol. 38(1), pp. 96-103, 2012. Doi: doi.org/10.1016/j.energy.2011.12.030.

[2] E. Welch, and D. Barnum, "Joint environmental and cost efficiency analysis of electricity generation”, Ecological Economics, vol. 68, pp.2326-2343, 2009. Doi:10.1016/j.ecolecon.2009.03.004.

[3] A. Mardani, D. Streimikiene, T. Balezentis, M. Z. M. Saman, Kh. M. Nor, and S. M. Khoshnava, "Data Envelopment Analysis in Energy and Environmental Economics: An Overview of the State-of-the-Art and Recent Development Trends", Energies. vol. 11, 2018. [Online]. Available: https://www.researchgate.net/publication/326736084_Data Envelopment_Analysis_in_Energy_and_Environmental_Economics _An_Overview_of_the_State-of-the-Art_and_Recent_Development_ Trends. Accessed on: June 19, 2019.

[4] O. Savko, "Data envelopment analysis implementation regarding gasdistribution enterprises' performance evaluation”, L'Association 1901 “SEPIKE”, vol. 5, pp. 192-195, 2014.

[5] J. Zorić, N. Hrovatin, and G. Scarsi, "Gas distribution benchmarking of utilities from Slovenia, the Netherlands and the UK: an application of Data Envelopment Analysis", South East European Journal of Economics and Business, vol. 4(1), pp. 113-124, 2009. Doi:10.2478/v10033-009-0008-1.

[6] S. J. Sadjadi, H. Omrani, S. Abdollahzadeh, M. Alinaghian, and H. Mohammadi, "A robust super-efficiency data envelopment analysis model for ranking of provinvial gas companies in Iran", Expert Systems with Applications, vol. 38, pp. 10875-10881, September 2011. Doi:10.1016/j.eswa.2011.02.120.

[7] E. Pourjavad, and H. Shirouyehzad, "A data envelopment analysis approach for measuring the efficiency in continuous manufacturing lines", International Journal of Services and Operations Management, vol. 18, no. 2, pp. 142-158, 2014. Doi: 10.1504/IJSOM.2014.061998.

[8] M. Toloo, B. Sohrabi, and S. Nalchigar, "A new method for ranking discovered rules from data mining by DEA", Expert Systems with Applications, vol. 36, no. 4, pp. 8503-8508, 2009.

[9] Z. Shokrollah, and R. Sadigh, "Ranking efficient DMUs using minimizing distance in DEA", Journal of Industrial Engineering International, vol. 12, iss: 2, pp. 237-242, 2016.

[10] G. I. Farantos, "The Data Envelopment Analysis Method and the influence of a phenomenon in organizational Efficiency: A literature review and the Data Envelopment Contrast Analysis new application", Journal of Data Envelopment Analysis and Decision Science, no. 2, pp. 101-117, 2015. Doi:10.5899/2015/dea-00098.

[11] A. Charnes, W. W. Cooper, and E. Rhodes, "Measuring the efficiency of decision making units", European Journal of Operational Research, vol. 2, pp. 429-444, 1978.

[12] R. D. Banker, A. Charnes, and A. A.Cooper, "Some models for estimating technical and scale inefficiencies in data envelopment analysis", Management Science, vol. 30, pp. 1078-1092, 1984.

[13] A. G. Goncharuk, "What causes increase in gas price: the case of Ukraine", International Journal of Energy Sector Management, vol. 7, pp. 448-458, 2013. Doi:10.1108/IJESM-03-2013-0003.

[14] P. Andersen, and N. C. Petersen, "A procedure for ranking efficient units in data envelopment analysis", Management Science, vol. 39 (10), pp. 1261-1264, 1993.

[15] R. G. Dyson, and E. Thanassoulis, "Applied in Data Envelopment Analysis", Journal of the Operational Research, vol. 52(1), pp. 1-15, 1991. 